Nota

\title{
PROGRAMA MULTIMÍDIA PARA FABRICAÇÃO DO AÇÚCAR CRISTAL DE CANA-DE-AÇÚCAR
}

\author{
Tadeu Alcides Marques ${ }^{1 *}$; Gil Eduardo Serra² \\ ${ }^{1}$ Faculdade de Agronomia/UNOESTE, Rod. Raposo Tavares km 572, CEP: 19067-175 - Presidente Prudente, SP. \\ ${ }^{2}$ Depto. de Tecnologia de Alimentos - FEA/UNICAMP, C.P. 6121 - CEP: 13081-970 - Campinas, SP. \\ *Autor correspondente <tmarques@agro.unoeste.br>
}

\begin{abstract}
RESUMO: Os cálculos para projetos de usinas de açúcar, os testes em laboratório de situações reais dentro das indústrias e as atividades de ensino na tecnologia da fabricação de açúcar e álcool são árduas tarefas de execução, seja pela complexidade dos cálculos, grandes variações de equipamentos e processos, como as difíceis tarefas de descrição dos equipamentos participantes dos processos. O presente trabalho tem como objetivo a apresentação e disponibilização de software multimídia bem como a descrição técnica de seu desenvolvimento, cuja função é auxiliar o ensino do processo tecnológico e cálculos em usinas de açúcar. O programa é direcionado a professores, engenheiros e alunos da área. Devido ao grande avanço da informática, possibilitando novos recursos visuais e agilizando o processo de imagens e de cálculo, optou-se pelo desenvolvimento do programa em ambiente MS-Windows 95 utilizando a linguagem Delphi versão 3, os quais permitem a visualização didática de fotos, filmes animados, equações, gráficos e textos técnicos. A característica deste programa é a possibilidade de fácil acesso a imagens e animações que facilitam o entendimento e por conseguinte o aprendizado das operações. O programa permite ainda simulações "on line" do processo e pode ser utilizado como módulo expansível para atender a situações mais específicas e detalhadas dos usuários. Palavras-chave: açúcar, cana-de-açúcar, tecnologia, multimídia, simulação
\end{abstract}

\section{MULTIMEDIA SOFTWARE FOR CALCULATIONS OF WHITE SUGAR MANUFACTURE}

\begin{abstract}
Our objective was the preparation of a multimedia software, which may be used for teaching and calculations in sugar mills. The program is very useful for teachers, engineers and students. Progress in computer sciences makes new visual resources and calculation procedures possible. The Software was developed in MS-Windows 95 with the Delphi 3 language. One characteristic of this program is the easy access to images and the simulated calculations that facilitate the understanding.

Key words: sugar, sugarcane, technology, multimedia, simulation
\end{abstract}

\section{INTRODUÇÃO}

No ensino do processamento da cana-de-açúcar para a fabricação do açúcar, a grande dificuldade, se não a maior delas é em sala de aula descrever os equipamentos e seu funcionamento para alunos que não estão familiarizados com este processo. Além disto, cálculos que até há algum tempo eram exaustivos e difíceis, atualmente com o uso da informática tornaramse simples de serem processados. É fato notório que a informática está se tornando a alavanca propulsora de muitas áreas, nas quais grande quantidade de informações são necessárias e a rapidez de acesso das mesmas são de suma importância prática. O setor sucroalcooleiro, como tantos outros, necessita de programas utilitários para uso e obtenção de soluções de problemas no processamento industrial nos quais são necessários cálculos e comparações que permitam interferir no processamento com rapidez, segurança e eficiência.
Desde a colheita e recebimento da cana-deaçúcar, em uma usina açucareira, até o empacotamento e armazenamento do açúcar, diversas etapas são necessárias, sendo que em todas elas estão presentes equipamentos e processos importantes para a boa qualidade do produto final. O processo de fabricação de açúcar está em contínua evolução e as práticas adotadas nas usinas brasileiras muitas vezes estão a frente dos principais manuais técnicos. Neste contexto o presente projeto buscou informações diretamente em unidades produtoras de modo a apresentar um retrato atual da tecnologia em uso. Sua estrutura permite a substituição ou incorporação de novas técnicas de forma simples e praticamente sem custos, disponibilizando rapidamente informações atuais para os interessados.

Fehr (1992) em seu relato permitiu extrair a idéia de que a informática ao colocar em confronto as informações do projetista de equipamento e do engenheiro de processo e produção, permite o "feedback" de dados e avaliações que antes eram mais difíceis. 
Segundo Nogueira \& Ramires (1991), os técnicos do setor sucroalcooleiro procuram produtividade associada à qualidade do produto final, seja ele açúcar ou álcool. Os técnicos sabem que um ineficiente gerenciamento nos setores de energia elétrica, ar comprimido, gerador de vapor, sistema de água etc., causam impacto negativo no processo, na produção e nos custos. Portanto um acompanhamento dos equipamentos em tempo real é de interesse.

Cálculos de dimensionamento de equipamentos e para monitoramento de processos são desenvolvidos por vários autores e especificamente para o setor sucroalcooleiro, e envolvem as mais diversas operações unitárias diretamente na fabricação e até mesmo em sistemas auxiliares (vapor e tratamento de efluentes, p.e.), podendose citar as principais fontes de consulta e referências utilizadas atualmente: Jenkins (1966), Hugot (1977a, b), Baikow (1982), $1^{\circ}$ e $2^{\circ}$ Seminários de Tecnologia Industrial (1983; 1985) e Payne (1989), que apresentam os cálculos de equipamentos e sistemas, bem como a descrição de condições operacionais de processos; abrangendo todas as operações de fabricação de açúcar.

Portanto, o objetivo deste trabalho é a divulgação das ferramentas, sistemas e estratégias utilizadas na elaboração de um software multimídia, mostrando as possibilidades de montagens que contenham desde textos até fotos, filmes animados e fluxogramas interativos com cálculos de simulação de diversos fatores interligados diretamente ou não.

\section{MATERIAL E MÉTODOS}

Utilizou-se um microcomputador modelo "PENTIUM MMX" de 233 Megahertz, com drive de CDROM 24x, drive de cd-rom recorder para gravação de CD, placa para TV (entrada e saída para filmadora e vídeo); memória de 64 megabytes; Disco Rígido com capacidade de 6,4 gigabytes; monitor super VGA de 15", com placa de vídeo de 4 megabytes; scanner colorido de mesa; impressora; filmadora de vídeo; videocassete; sistema operacional Windows 95; software - Borland Delphi 3,0 Client/Server Suite.

Os cálculos de dimensionamento das etapas da produção foram realizados segundo Jenkins (1966), Hugot (1977a, b), Zarpelon (1976), Hulett (1976), Baikow (1982), $1^{\circ}$ e $2^{\circ}$ Seminários de Tecnologia Industrial (1983; 1985), Payne (1989) e Marques (1993).

Para a elaboração do programa e dos textos ocorreram visitas nas unidades industriais, onde foram realizadas entrevistas, filmagens e fotos além da consulta na literatura citada. Também foram visitadas empresas produtoras de equipamentos. Na elaboração final do software foi utilizada a confecção de um algoritmo segundo Verzello \& Reutter (1984a, b), e com técnicas de modelagem orientadas ao objeto segundo Rumbaugh et al. (1994), com a sua transcrição para a linguagem DELPHI de acordo com Cantú (1996), sendo utilizado recursos de multimídia, com a gravação do produto final em Disco Compacto (CD).

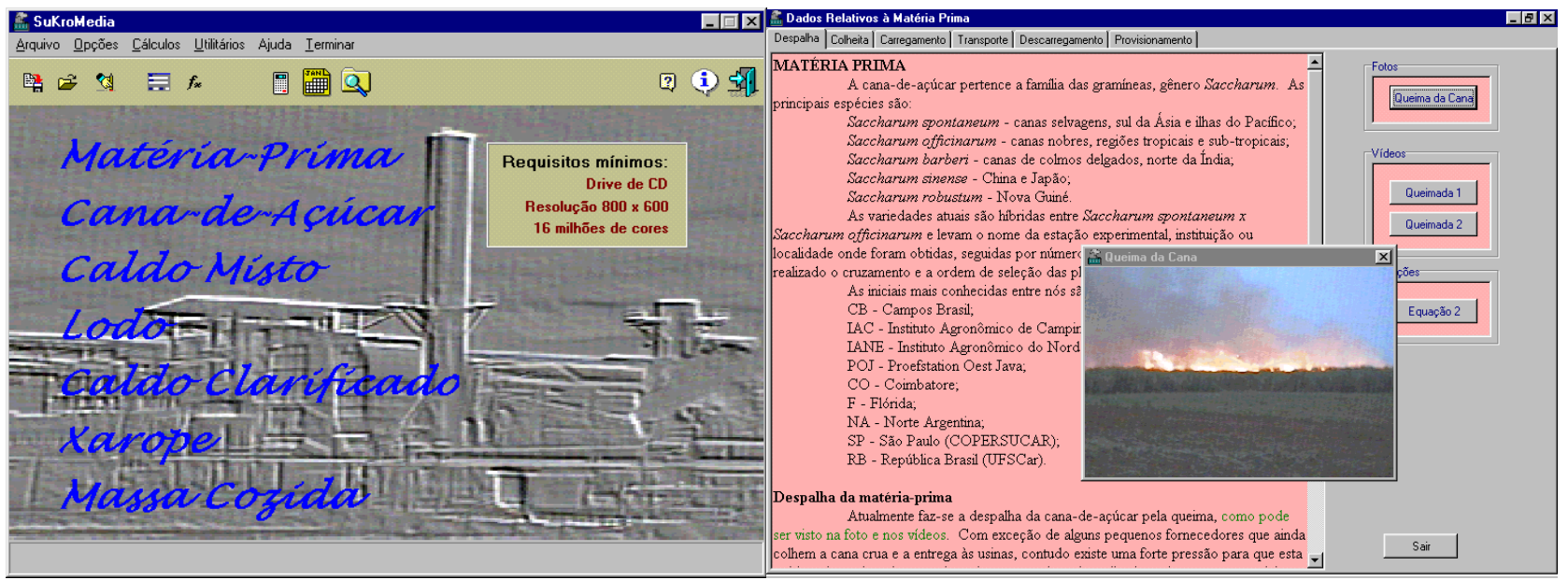

Figura 1 - Janela principal do programa SukroMedia e janela secundária do programa SukroMedia, mostrando texto e foto de canavial em queima.

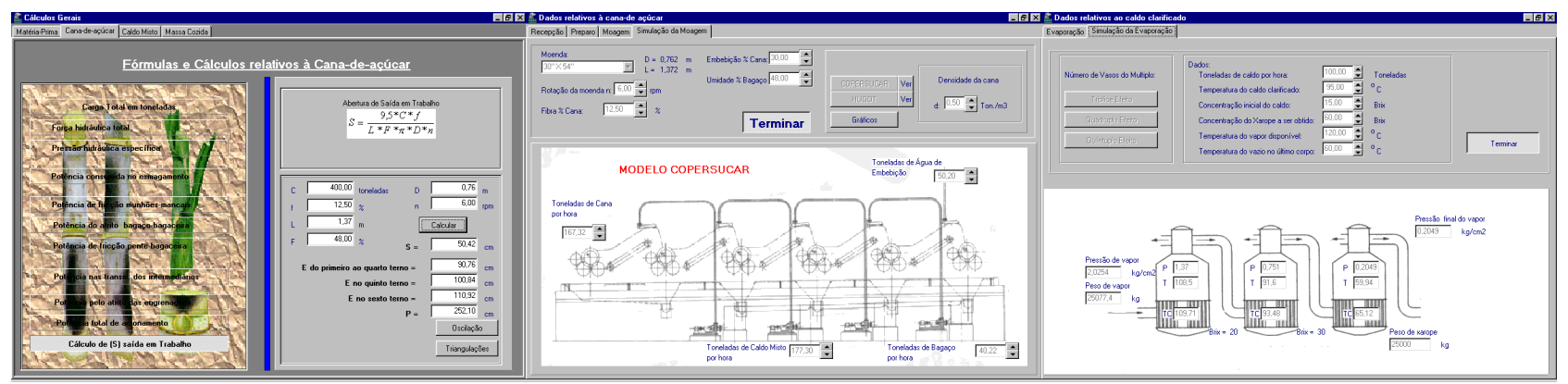

Figura 2 - Janelas secundárias referentes aos cálculos e simulação da moagem e evaporação. 


\section{RESULTADOS E DISCUSSÃO}

O software elaborado, denominado SukroMedia, é direcionado aos profissionais e estudiosos da área sucroalcooleira, sendo que o mesmo apresenta em sua inicialização a Janela Principal (Figura 1). A partir desta Janela Principal pode-se selecionar uma das opções da tela (Matéria Prima, Cana-de-açúcar, Caldo Misto, Lodo, Caldo Clarificado, Xarope e Massa Cozida) que levam a partes específicas do programa, as quais são compostas de textos, fotos, filmes, fluxogramas e equações e cálculos "on-line", como pode ser visto na Figura 1. O resultado do trabalho de digitalização de fotos e imagens animadas no SukroMedia mostrou uma arte final certamente com possibilidades de ser significativamente melhorada, possivelmente com o emprego de softwares específicos e com melhores recursos, como o Adobe Première.

A partir da janela principal pode-se também selecionar a opção "Cálculos Gerais", que leva a uma seção do programa que permite acessar equações e cálculos "on line", para atender a dimensionamento e simulação, como pode ser visto na Figura 2. Nas opções "Cana-de-Açúcar" e "Caldo Clarificado" podem ser encontradas seções que permitem cálculo "on line" e simulações, montados em conjunto com o fluxograma esquemático, como mostrado na Figuras 2.

\section{AGRADECIMENTOS}

À FAPESP - Fundação de Amparo à Pesquisa do Estado de São Paulo, pelo apoio dado à elaboração do Projeto até esta fase, com a concessão de Bolsa de PósDoutorado ao Dr. Tadeu Alcides Marques e concessão do auxílio financeiro para a execução do projeto.

\section{REFERÊNCIAS BIBLIOGRÁFICAS}

BAIKOW, V.E. Manufacture and refining of raw cane sugar. 2.ed. Amsterdam: Elsevier, 1982. 588p. (Sugar Series, 2)
CANTÚ, M. Dominando o Delphi 2: a bíblia. São Paulo: Makron Books, 1996. 912p.

FEHR, M. Uma filosofia de automação para a destilaria. Álcool \& Açúcar, v.12, p.24-33, 1992.

HUGOT, E. Manual da engenharia açucareira. São Paulo: Mestre Jou, 1977a. v.1, 544p.

HUGOT, E. Manual da engenharia açucareira. São Paulo: Mestre Jou, 1977b. v.2, 1198p.

HULETT, D.J.L. Controle automático e instrumentação usados no processamento da cana-de-açúcar. In: SEMINÁRIO COPERSUCAR DA AGROINDÚSTRIA AÇUCAREIRA, 4., Piracicaba, 1976. Anais. Piracicaba: Copersucar, 1976. p. $417-424$

JENKINS, G.H. Introduction to cane sugar technology. Amsterdam: Elsevier, 1966. 478p.

MARQUES, T.A. Processamento de dados: aplicações em problemas de ciências agrárias. Marília: UNIMAR, 1993. v.1, $83 p$.

NOGUEIRA, J.C.; RAMIRES, M.C. Gerenciamento de águas em usinas e destilarias. Álcool \& Açúcar, v.11, p.20-23, 1991.

PAYNE, J.H. Operações unitárias na produção do açúcar de cana. São Paulo: Nobel, 1989. 245p.

RUMBAUGH, J.; BLAHA, M.; PREMERLANI, W.; EDDY, F.; LORENSEN, W. Modelagem e projetos baseados em objetos. Rio de Janeiro: Campus, 1994. 652p.

SEMINÁRIOS DE TECNOLOGIA INDUSTRIAL, 1., Piracicaba, 1983. Anais. Piracicaba: Copersucar, 1983. 483p.

SEMINÁRIOS DE TECNOLOGIA INDUSTRIAL, 2., Piracicaba, 1985. Anais. Piracicaba: Copersucar, 1985. 648p.

VERZELLO, R.J.; REUTTER, J. Processamento de dados: conceitos básicos; hardware. São Paulo: McGraw-Hill, 1984a. v.1, 243p.

VERZELLO, R.J.; REUTTER, J. Processamento de dados: sistemas de informação; software - basic. São Paulo: McGraw-Hill, 1984b. v.2, 544p.

ZARPELON, F. Planejamento da seção de cozimento. In: SEMINÁRIO COPERSUCAR DA AGROINDÚSTRIA AÇUCAREIRA, 4., Piracicaba, 1976. Anais. Piracicaba: Copersucar, 1976. p.371-376. 